\title{
Discovery of a new antiviral protein isolated Lonomia obliqua analysed by bioinformatics and real-time approaches
}

\author{
Ana Carolina Viegas Carmo • Lilian Hiromi Tomanari Yamasaki • \\ Cristina Adelaide Figueiredo • Dalton Nogueira da Silva Giovanni • \\ Maria Isabel de Oliveira - Fabiana Cristina Pereira dos Santos • \\ Suely Pires Curti · Paula Rahal • Ronaldo Zucatelli Mendonça
}

Received: 9 December 2013/ Accepted: 3 May 2014/Published online: 8 June 2014

(C) Springer Science+Business Media Dordrecht 2014

\begin{abstract}
This study presents a new recombinant protein that acts as a powerful antiviral (rAVLOrecombinant Antiviral protein of Lonomia obliqua). It was able to reduce the replication by $10^{6}$ fold for herpes virus and by $10^{4}$ fold for rubella virus. RT-PCR of viral RNA rAVLO treated infected cells also showed similar rate of inhibition in replication. The analysis of this protein by bioinformatics suggests that this protein is globular, secreted with a signal peptide and has the ability to bind to MHC class I. It was found that there are several protein binding sites with
\end{abstract}

Ana Carolina Viegas Carmo, Lilian Hiromi Tomanari Yamasaki and Cristina Adelaide Figueiredo have contributed equally to the preparation of this manuscript.

A. C. V. Carmo $(\bowtie)$. D. N. da Silva Giovanni .

R. Z. Mendonça

Laboratório de Parasitologia, Instituto Butantan,

São Paulo Cep. 05503-000, Brazil

e-mail: viegasacc@gmail.com

L. H. T. Yamasaki - D. N. da Silva Giovanni - P. Rahal Laboratório de Estudos Genômicos, IBILCE-UNESP, São Paulo, Brazil

C. A. Figueiredo · D. N. da Silva Giovanni ·

M. I. de Oliveira · F. C. P. dos Santos

Núcleo de Doenças Respiratórias, Centro de Virologia, Instituto Adolfo Lutz, São Paulo, Brazil

D. N. da Silva Giovanni - S. P. Curti

Núcleo de Doenças de Transmissão Vetorial, Centro de Virologia, Instituto Adolfo Lutz, São Paulo, Brazil various HLA and a prevalence of $\alpha$-helices in the $\mathrm{N}$-terminal region (overall classified as a $\alpha / \beta$ protein type). BLAST similarity sequence search for corresponding cDNA did not reveal a similar sequence in Genbank, suggesting that it is from a novel protein family. In this study we have observed that this recombinant protein and hemolymph has a potent antiviral action. This protein was produced in a baculovirus/Sf-9 system. Therefore, these analyses suggest that this novel polypeptide is a candidate as a broad spectrum antiviral.

Keywords Antiviral - Lonomia obliqua .

Bioinformatics

\section{Introduction}

Viral infections are a subject of considerable interest, especially in the human, animal and plant health fields. Because there are still many diseases with no efficient treatment available, the search for new strategies is extremely important. Development of these agents are also important to overcome the frequent occurrence of micro-organisms resistant to drugs (Lohner and Staudegger 2001). Therefore, new therapies for human viral diseases strongly rely on the discovery of new therapeutic agents (Kao et al. 2010). For influenza treatment, for example, there are four antiviral agents approved and currently in use. However, Kao and coworkers (2010) already 
reported that $\mathrm{H} 1 \mathrm{~N} 1$ could easily develop resistance to Tamiflu, based on gene sequencing and structure prediction of neuraminidase. Zanamivir is an agent which also belongs to the neuraminidase inhibitor class and it is active against influenza A and B. The drugs amantadine and rimantadine belong to the adamantane class known as being effective only against influenza A virus (Fiore et al. 2011). Antiviral activity is also described in many bioproducts which are investigated for new drug development. These products can be produced by animals, plants or bacteria. Nowadays, development of new therapies for important diseases such as AIDS (Acquired Immuno Deficiency Syndrome) and those caused by new strains of viruses (SARS Coronavirus, Influenza viruses $\mathrm{H} 5 \mathrm{~N} 1$ and $\mathrm{H} 1 \mathrm{~N} 1$ ) is a major topic (Delcroix and Riley 2011; Heinen and da Veiga 2011).

Insects can be highlighted in this scenario. Several studies have demonstrated the antiviral effect of substances synthetized by this group. The fact that these organisms are found inhabiting all the planet ecosystems, leads to believe that they have developed protection mechanisms to survive in these places. Susceptible to a variety of viral infections, insect resistance mechanisms are at present little known. Identification of these pathways stimulates the search for new agents which can be applied to human infections (Chernysh et al. 2002; Yao et al. 2006). Antiviral activity molecules are found in different compounds and insect species (Chernysh et al. 2002; Cueto et al. 2011; Ourth 2004; Popham et al. 2004). A recently identified protein (AVLO) of approximately $20 \mathrm{kDa}$, purified from the hemolymph of Lonomia obliqua is able of inhibiting the replication of measles, polio and influenza viruses when added to the cell cultures $1 \mathrm{~h}$ before infection (Greco et al. 2009). It was observed in this study that the hemolymph does not show any virucidal effect, suggesting that it may act at different stages of virus replication.

In another study, this protein was successfully expressed in the baculovirus system and the antiviral activity was tested. It showed that the purified recombinant protein could significantly reduce viral replication (10,000 times) of a Picornavirus (EMC) (Carmo et al. 2012).

Therefore, the antiviral activity confirmation and development of in vitro expression led us to proceed to the investigation of these new protein features. Further understanding of structure, function and mechanism of action of this macromolecule are essential to evaluate its potential to be established as a wide range antiviral agent.

In the present study, we tested the antiviral activity in Herpes and Rubella virus, characterized physics and biologic properties of a novel protein from $L$. obliqua hemolymph by different in silico approaches. This protein presented antiviral activity for several virus infections in cell culture, described in previous studies of our group (Carmo et al. 2012; Greco et al. 2009). Therefore, this protein property instigates our attention as a potential new antiviral drug and elucidating its properties and mechanisms of actions is a great step in drug development.

\section{Materials and methods}

Analytical procedures

Cells

The SIRC cells (rabbit cornea-CCL-60 from ATCC (Manassas, VA, USA)) and the Vero cell lines (African green monkey kidney- ATCC CCL-81) were grown in $75 \mathrm{~cm}^{2}$ plastic cell culture flasks, in DMEM medium (Dulbecco's minimum Eagle essential medium) supplemented with $10 \%$ inactive fetal bovine serum (FBS), $20 \mathrm{mM}$ L-glutamine (Invitrogen, Carlsbad, CA, USA).

\section{Hemolymph}

For this study, the hemolymph of L. obliqua was collected from sixth instar larvae after setae had been cut off and its purified fractions were obtained from gel filtration chromatography system as described by Greco et al. (2009).

\section{Determination of the cytotoxic effect}

The cytotoxic effects of the hemolymph were assessed by using a standard VERO cell assay. The confluent cell cultures were exposed to different amounts of hemolymph $(0.5,1,2,5$ and $10 \%, \mathrm{v} / \mathrm{v})$ and incubated for $72 \mathrm{~h}$ in triplicates. Analysis where performed at 24, 48 and $72 \mathrm{~h}$ of incubation. Daily, the supernatants were removed and the remaining living cells were counted after being fixed and stained with crystal 
violet $(0.2 \%$ in methanol $20 \%)$. Cytotoxicity percentage values were calculated by the formula: $\left(\mathrm{A}_{\text {control }}-\mathrm{A}_{\text {sample }} / \mathrm{A}_{\text {control }}\right) \times 100$. Data are expressed as the mean \pm SD. Statistical analysis was performed using the Student's $t$ test and the level of significance was set at $p \leq 0.05$.

\section{Antiviral recombinant protein ( $r A V L O)$}

The antiviral protein used in this study was a recombinant protein from L. obliqua expressed in a baculovirus/insect cell system as described by Carmo et al. (2012).

\section{Antiviral effect of hemolymph and of a recombinant protein (rAVLO) on infected cells}

Vero and SIRC cells were cultivated to approximately $90 \%$ confluence in 96 well plates in DMEM, supplemented with $2 \mathrm{mM} \mathrm{L}$-glutamine and $10 \%$ FCS. Plates were incubated at $37{ }^{\circ} \mathrm{C}$ in a humidified $5 \% \mathrm{CO}_{2}$ atmosphere. The confluent cells were inoculated with $10 \mu \mathrm{L}$ of the purified hemolymph, clone 5 (an empty bacmid) and the recombinants 10 (rAVLO clone 10), 16 (rAVLO clone 16) or 23 (rAVLO clone 23) in duplicate. After $1 \mathrm{~h}$ of incubation, these cells were infected with viruses from the infected cultures, at dilutions of $10^{-1}-10^{-7}$ for rubella virus and $10^{-5}$ $10^{-12}$ for herpes virus Following, they were incubated as previously described for 4 days. In addition, for the determination of the hemolymph effect on the infected cells, real time PCR was performed.

\section{Determination of the virus infectious dose}

The confluent monolayers were dispersed with $0.2 \%$ trypsin and $0.02 \%$ versene, and re-suspended in DMEM growth medium with $100 \mathrm{IU} / \mathrm{ml}$ penicillin G and $100 \mathrm{mg} / \mathrm{ml}$ streptomycin. For the preparation of 96 well plates, the cell suspension was diluted to $2.0 \times 10^{4}$ cells $/ \mathrm{ml}$. Plates were seeded with $200 \mu \mathrm{L}$ of suspension and incubated at $37{ }^{\circ} \mathrm{C}$ in a humidified $5 \% \mathrm{CO}_{2}$ atmosphere. RA 27/3 strain (Meruvax II, Merck, Sharp and Dohme) and herpes simplex virus strain (Mc Intyre) stock virus were quantified by medium tissue-culture infections with $0.01 \mathrm{MOI}$ (multiplicity of infection) on cell cultures. The confluent cell cultures were inoculated with a $100 \mu \mathrm{L}$ diluted virus in quadruplicates, for each cell line. After
$1 \mathrm{~h}$ adsorption at room temperature, each well received $200 \mu \mathrm{L}$ of DMEM medium with $2 \%$ FBS. Uninfected cultures were also prepared and treated identically as controls. Plate cultures were observed for CPE daily during 7 days, when the test was concluded. Fifty per cent infectivity end points were calculated by the method of Reed and Muench (1938). All titers are given as $\log 10 \mathrm{TCID}_{50}$ per $0.1 \mathrm{~mL}$ of virus.

\section{Cytopathic effect (CPE) reduction assay}

Vero and SIRC cells were seeded into 96 well plates at $2 \times 10^{4}$ cell per well and incubated during $48 \mathrm{~h}$ at $37{ }^{\circ} \mathrm{C} 5 \% \mathrm{CO}_{2}$. The confluent cells were inoculated with $10 \mu \mathrm{L}$ of the purified hemolymph, an empty bacmid (clone 5) and the recombinant clones (rAVLO clone 10, rAVLO clone 16 and rAVLO clone 23) (Carmo et al. 2012), and incubated at $37^{\circ} \mathrm{C}$ in a humidified $5 \% \mathrm{CO}_{2}$ atmosphere. After $1 \mathrm{~h}$, these cells were infected with viruses from the infected cultures, at dilutions rate of $10^{-1}-10^{-7}$ for rubella virus and $10^{-5}-10^{-12}$ for herpes virus.

Plaque formation was assessed after 5 days by staining with crystal violet after fixation of the cells with $3 \%$ paraformaldehyde. The number of plates was counted manually. The PFU numbers were presented as average of duplicate samples. The experiment was repeated at least three times.

\section{Quantitative real-time PCR assay}

Total RNA was extracted from $200 \mu \mathrm{L}$ of each type culture infected and non infected using the MagNA Pure extractor (Roche, Basel, Switzerland). For rubella virus, RT-PCR was performed using Superscript III Step RT-PCR (Invitrogen), according to the manufacturer's recommendations. To amplify a 185-nucleotide region in the E1 coding region nucleotides 8,807-8,991 described by Abernathy et al. (2009). The assay was performed in triplicate with $25 \mu \mathrm{l}$ reactions mixtures containing reaction buffer (Invitrogen), $0.5 \mu \mathrm{l}$ of a Superscript-Taq enzyme mixture, $0.2 \mu \mathrm{M}$ of each primer, $0.1 \mu \mathrm{M}$ of the labeled probe (Invitrogen) and $5 \mu \mathrm{l}$ of RNA. This assay was carried out in triplicate for each sample, including a no-template control. The thermal cycling was carried out with an Applied Biosystems 7500 thermal cycle with $50{ }^{\circ} \mathrm{C}$ for $10 \mathrm{~min} ; 95^{\circ} \mathrm{C}$ for 2 min and 40 cycles 
of $95{ }^{\circ} \mathrm{C} 15 \mathrm{~s}$ and $60{ }^{\circ} \mathrm{C} 1 \mathrm{~min}$. The presence of intact RNA in the samples was confirmed with specific primes for RNAseP RNA (Emery et al. 2004). Four positive controls containing known copy numbers of transcribed RV RNA were run on each plate as quantitation standards. A reaction mixture containing water as the template was run on each plate as negative control. The data were analyzed with SDS software (version 2.1 AB). Herpes simplex virus quantitative real time PCR assay using primers described by Read and Kurtz (1999). For the real time PCR, the $20 \mu \mathrm{l}$ solution containing $12 \mu \mathrm{l}$ of the $\mathrm{SYBR}^{\circledR}$ Green PCR Master Mix (Applied Biosystems, Foster City, CA USA), $10 \mu \mathrm{M}$ of each primer, $6.5 \mu \mathrm{H}_{2} \mathrm{O}$, and $5 \mu \mathrm{l}$ cDNA. Cycling conditions were as follows: $94{ }^{\circ} \mathrm{C}$ for 5 min, followed by 35 cycles of $94{ }^{\circ} \mathrm{C}$ for $30 \mathrm{~s}, 57^{\circ} \mathrm{C}$ for $20 \mathrm{~s}$ and $72{ }^{\circ} \mathrm{C}$ for $40 \mathrm{~s}$.

Bioinformatics

\section{Sequence}

The cDNA nucleic acid and respective amino acid sequence of the antiviral activity protein were obtained from Genbank (Acess number: JN807330). The antiviral activity and sequence were described in previous published works (Carmo et al. 2012; Greco et al. 2009). All sequence editions were performed in Bioedit $^{\circledR}$.

\section{Sequence similarity search}

The cDNA and amino acid sequences were submitted to BLASTp (Basic Local Alignment Search Tool) in order to identify regions with similarity with sequences already described in the literature.

\section{Structural predictions}

In first instance, to determine if this sequence could be related to intrinsically unstructured type of proteins, we used the Intrinsically Unstructured Predictor Server (IUPRED). This technique estimates pairwise energy from amino acid composition and classifies between folded and disordered proteins. Three types of prediction can be performed: long disorder, short disorder and structured regions for the query sequence and for a protein which is known to have determined structured and disordered regions (Hepatitis $\mathrm{C}$ virus
Non-structured 5A region, Genbank access number: NC004102). IUPRED can be accessed at http://iupred. enzim.hu/ (Dosztanyi et al. 2005).

Prediction of secondary structure types (helix, sheet and coil) was performed using different approaches, disponible at Phyre and PredictProtein platforms. Postranslational modifications sites were performed using Prosite, on PredictProtein server. Phyre is disponible at http://www.sbg.bio.ic.ac.uk/phyre/ (Kelley and Sternberg 2009). PredictProtein is available at https://www.predictprotein.org (Rost et al. 2004).

To verify the difficulty to get the structure of this protein experimentally, using protein crystallography, the sequence was submitted to XtalPred. This server predicts protein crystallizability analyzing several features of the protein. After computing these features, the program returns the results as an overall probability of crystallization. XtalPred is available at http:// ffas.burnham.org/XtalPred-cgi/xtal.pl (Slabinski et al. 2007).

\section{Protein signature, signal peptide and localization search}

We used the InterProScan Sequence Search tool from EMBL-EBI (http://www.ebi.ac.uk/Tools/pfa/iprscan/) to recognize in the sequence different protein signatures databases. InterProScan combines several methods with further refinement procedures and it is widely used for structural and functional classification (Hunter et al. 2012).

SignalP 4.0 Server was used to predict presence and localization of signal peptide cleavage sites. This method is based on a combination of several artificial neural networks (ANN) and is considered one of the best methods to search for signal peptides (Petersen et al. 2011).

In combination with SignalP, TargetP server predicts subcellular localization for eukaryotic proteins. The local assignment is based on the predicted presence of aminoterminal presequences (Emanuelsson et al. 2007). SignalP and TargetP are available at Center for Biological Sequences (CBS) website: http://www.cbs.dtu.dk/services/.

\section{Physical and chemical properties prediction}

Overall weight, pI (Isoeletric point) and GRAVY (Grand Average of Hydropathicity) were estimated by 
ProtParam (http://web.expasy.org/cgi-bin/protparam/ protparam). Protscale prediction server (http://web. expasy.org/protscale/) analyzed the sequence in order to predict several physical and chemical properties by different methods. Amino acid sequence was submitted in all available scales for polarity, hydrophobicity, accessibility and mutability in each residue position.

\section{Proteossome processing, MHC binding and epitope predictions}

To predict if in vivo this protein could have regions interacting with MHC NetCLT (http://www.cbs.dtu.dk/ services/NetCTL/) database was used to identify in the sequence peptide motifs that could bind. The method integrates prediction of peptide MHC class I binding, proteasomal $\mathrm{C}$ terminal cleavage and TAP transport efficiency. The server allows for predictions of CTL epitopes restricted to $12 \mathrm{MHC}$ class I supertype. MHC class I binding and proteasomal cleavage prediction is performed using artificial neural networks. TAP transport efficiency is predicted using weight matrix (Larsen et al. 2007). Only scores $>0.75$ (which means sensitivity of 0.8 and specificity of 0.94 ) were considered.

\section{Statistics analysis}

To verify if the differences between the prediction results were significant $(p<0.05)$, values were submitted to two-proportions test (Fisher's exact test) using the software MiniTab $^{\circledR}$ (Minitab Inc., State College, PA, USA).

\section{Results}

Analytical procedures

The hemolymph in concentrations lower than $2 \%$ (v/v) were not toxic to VERO and SIRC cells, since high percentages of viable cells were observed throughout the triplicates for cytotoxicity determination experiments.

The antiviral activity of the total hemolymph and recombinant clones were tested with rubella and herpes simplex viruses. Clones 5, 10, 16 and 23 were added to infected SIRC and VERO cells cultures $1 \mathrm{~h}$ prior the infection. The cells pre-treated with recombinant 10 and 23 showed a $1.000 .000 \times$ decrease in herpes virus titers in comparison to those in the control culture (cells without any treatment). Experiments carried out with the rubella virus showed similar results: the use of clone 16 caused a 10.0009 decrease in rubella virus titers. In summary, results from CPE reduction assay demonstrated that total hemolymph exhibited antiviral effects when it was added in pre-, post-infection and even simultaneously with the virus. The inhibitory effects of the total hemolymph were more powerful than when recombinants were tested. To identify any inhibitory effect of hemolymph on rubella and herpes replication, the viral genomic synthesis of rubella and herpes was compared between hemolymph treated and untreated infected cells. Total RNA and DNA extraction was performed after $96 \mathrm{~h}$ of rubella and herpes infection, and the intracellular viral load for both viruses were measured. Standard curves for the amplification were generated by a serial tenfold dilution of the template to evaluate the efficiencies of both reactions. The resulting standard curves showed that the amplification efficiencies for the genes were between 95 and $100 \%$ with correlation coefficients greater than 0.99 . The results of the qPCR showed a significantly increase in level of rubella and herpes transcription in the inoculated cells at 4 days after viral infection compared to the mock. Also, a reduction of rubella virus was observed in cells treated with rAVLO clone 16 and total hemolymph in dilutions of $10^{-4}, 10^{-5}, 10^{-6}, 10^{-7}, 10^{-8}$ (Fig. 1). Reduction of the herpes virus replication was observed in cells treated with recombinants 10,16 and 23 in dilutions of $10^{-10}, 10^{-11}$ and $10^{-12}$. In addition, total hemolymph completely inhibited the replication of herpes virus (Fig. 2).

\section{Bioinformatics}

\section{Sequence similarity search}

BLAST analysis of the cDNA sequence without the Histidine tail and TEV (tobacco etch virus) protease site (534 nucleic acids residues) resulted in identification of no sequence with similarity in Genbank. Respective protein sequence analysis, 178 amino acid residues, identified a low similarity region (41\%) with carnitine acetyl transferase (access numbers in Genbank: EGC43300.1; EEH08271.1; EER39656.1). The coverage of this region is from residues 97 until 138 of the query protein with residues 552 through 597 of the 


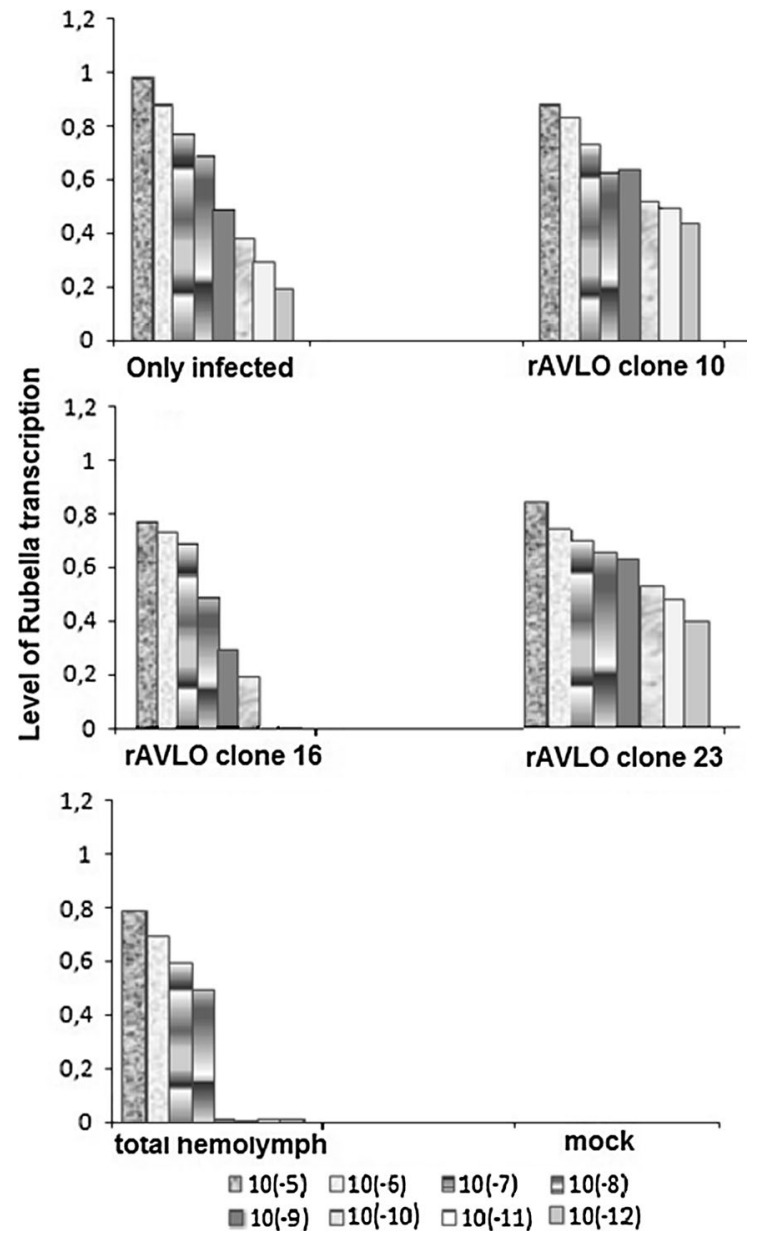

Fig. 1 Rubella virus transcription levels in cells treated with rAVLO clones and total hemolymph measured by real time PCR. Different virus concentrations were used (each bar)

reference sequences. No amino acid sequence covering full query sequence was encountered.

\section{Structure predictions}

IUPRED analysis indicated that this 178 amino acid sequence has an overall folded conformation. Therefore, it shows globular form. In details, the program returned no identified long regions with high disorder tendency (DT), with all positions below $45 \%$ of probability of DT. According to IUPRED, short disordered regions are possible between residues 79 and 81 and 176 and 178, disorder tendency was around 60 and $70 \%$, respectively. According to the two previous described predictions, IUPRED prediction for structured regions showed that all the protein

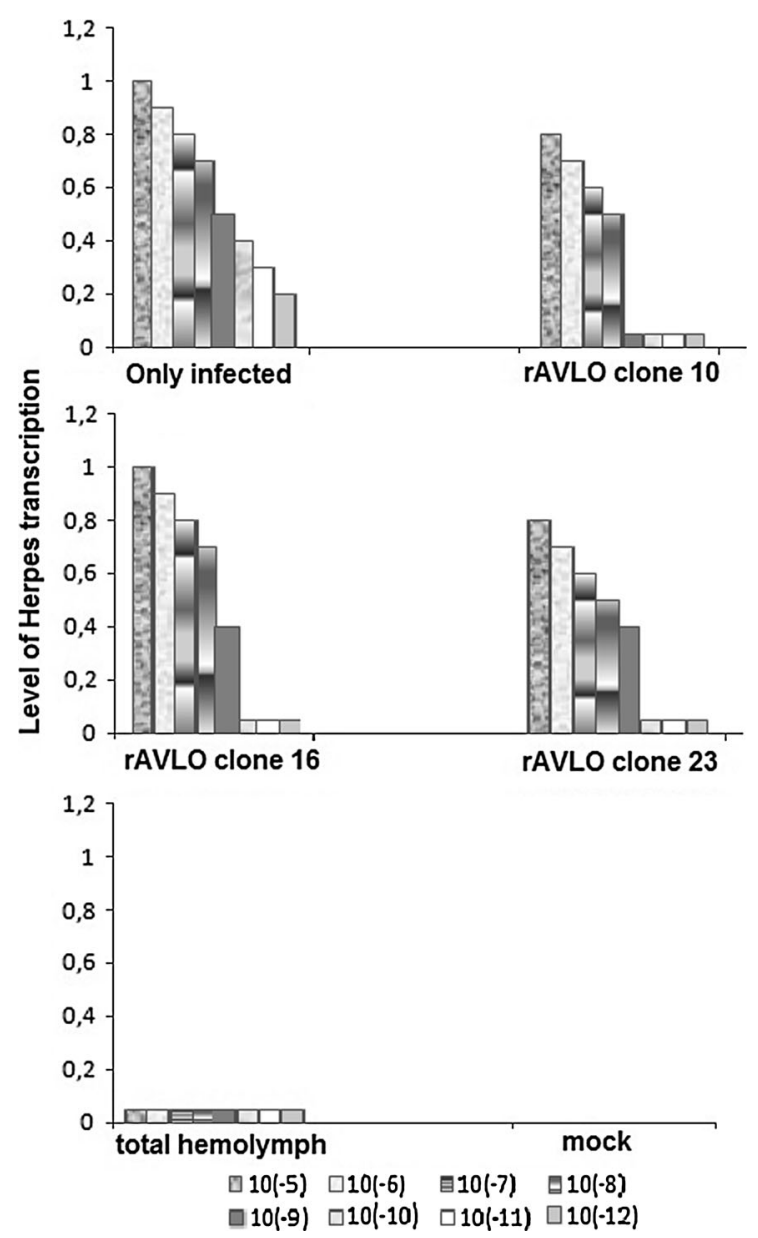

Fig. 2 Herpes transcription levels in cells treated with rAVLO clones and total hemolymph measured by real time PCR. Cells were treated with rAVLO clones and total hemolymph

extension has tendency to show globular structure. The results of the protein with known regions of structure/disorder were according to the results from experiments: a structured part (position 1-191) and a disordered region (from 192 to 448).

In summary, the query amino acid sequence was predicted by PredictProtein server to have alpha-beta type of second structure general architecture. In overall, the protein composition was $37.08 \%$ of helix, $29.21 \%$ of sheet and $33.71 \%$ of coil. The Phyre server, predicted the 2nd structure composition as $40 \%$ of helix, $24.86 \%$ of sheet and $35.14 \%$ of coil. Statistical analysis demonstrated that the results from these two serves have no significant difference $(0.4<p<0.9)$. 
Along the protein sequence, helix structure type was identified in at least two portions in N-terminal regions, with high confidence ( $>60 \%)$ : one between residues 01 and 15 and other between 79 and 95. In contrast, helix and coil structure types were identified distributed overall the sequence and did not comprehend as long portions as helix (maximum of 8 residues). Prosite analysis indicated phosphorylation and myristoylation modification sites. A summary of these predictions are shown in Fig. 3.

The prediction of the difficulty to obtain crystallography structure (XtalPred) from this protein, classified it as a sequence of median difficulty.

\section{Protein signature, signal peptide and cell localization search}

InterProScan identified only one known signature in amino acid sequence: a eukaryotic signal peptide at aminoterminal portion. In accordance, SignalP prediction showed more details of this sequence. The site with maximum cleavage probability is between residues 16 and 17 (99\% probability) at hydrogen-region.

Considering this result, TargetP predicted that this protein is secreted, with a pre-sequence length of 16 residues and reliability class of 2 . Reliability classes are divided from 1 to 5, where 1 indicates the strongest prediction. $\mathrm{RC}$ is a measure of the size of the difference ('diff') between the highest (winning) and the second highest output scores. Class 2 indicates that $0.800>$ diff $>0.600$.

\section{Physical and chemical properties prediction}

Overall protein molecular weight prediction resulted in $19.792 \mathrm{kDa}$. After cleavage, predicted by TargetP, there should be two resulting fragments of 1.734 and $18.075 \mathrm{kDa}$. Theoretical pI and GRAVY also changed in overall sequence and on predicted fragments: $\mathrm{pI}=5.98$ and GRAVY $=-0.094$ before cleavage; $\mathrm{pI}=7.98$ and GRAVY $=2.05$ for the small fragment; $\mathrm{pI}=4.99$ and GRAVY $=-0.306$ for the long fragment. Prediction of polarity and hydrophobicity by position (Protscale) indicates that this protein shows an aminoterminus which is highly hydrophobic/ nonpolar (until near residue 20). After this fragment, the sequence alternates from polar to nonpolar regions of around 15 residues of length, until residue 152 . The following carboxi terminus shows a slightly increase in hydrophobicity. The most polar/hydrophilic region is located between residues 70 and 120 (Figs. 4, 5). According to these results, prediction of accessible or buried residues shows a right probability of the most hydrophilic region to be exposed in the overall structure (Fig. 6).

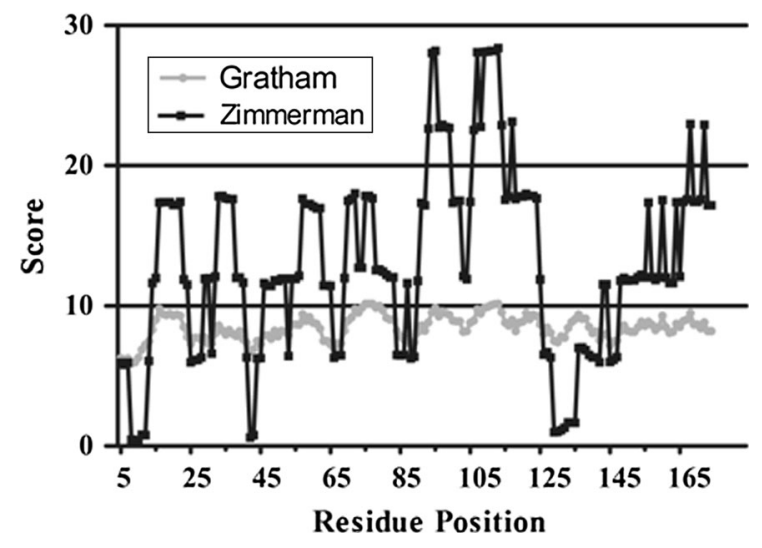

Fig. 4 Hydrophylic/polar prediction along the protein using Gratham and Zimmerman calculation methodologies. Higher values in both methods indicates higher hydrophylic/polar regions
Fig. 3 Second structure and posttranslational modifications sites predictions diagram in protein sequence. Each bar colored represents a second structure type and spaces represents coil/unstructured regions. Colored lines represents different sites predicted by Prosite. (Color figure online)

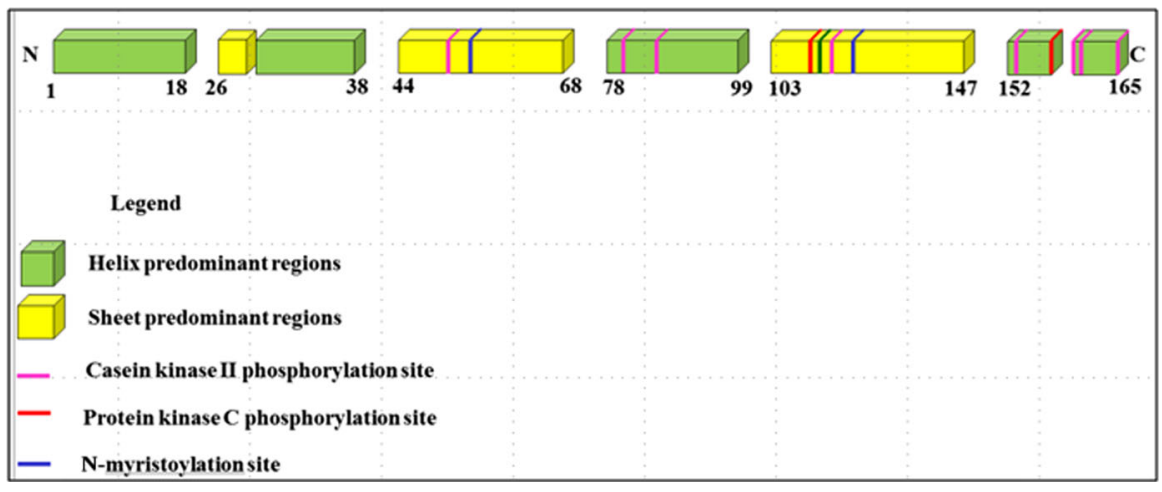



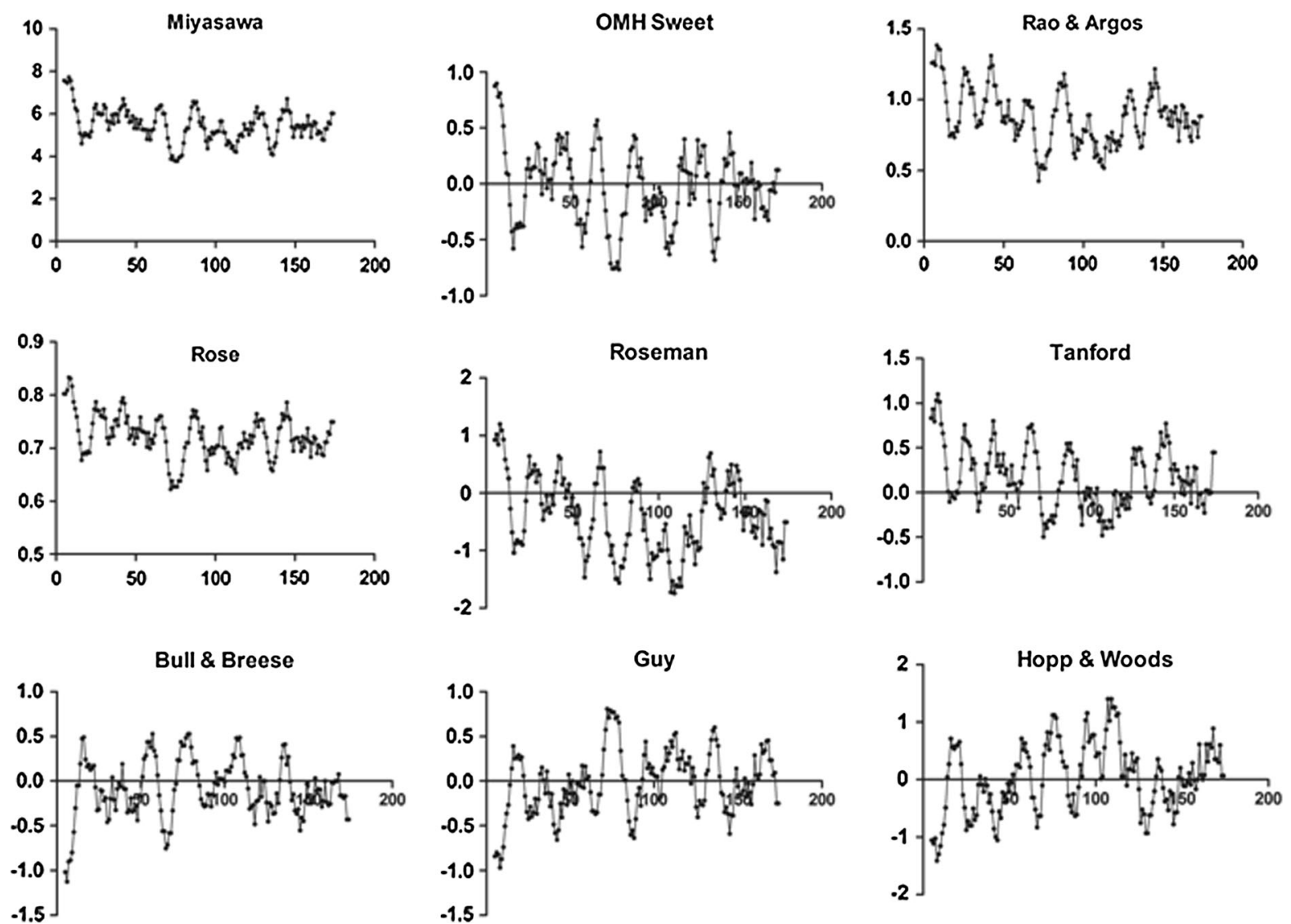

Fig. 5 Hydrophobic prediction along the protein using different methods. Higher values indicate higher hydrophobic regions in Miyasawa, OMH Sweet, Rao and Argos, Rose, Roseman and

Tanford methods; the opposite occurs in Bull and Breese, Guy and Hopp and Wodds predictions. $X$-axis residue position, $Y$ axis score calculated
Fig. 6 Protscale predictions for mutability, antigenicity and accessibility of each residue in the protein sequence
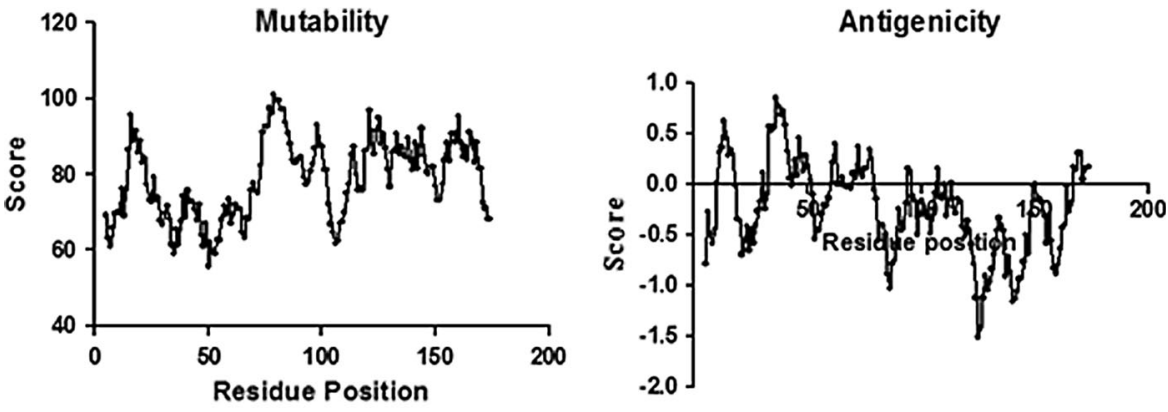

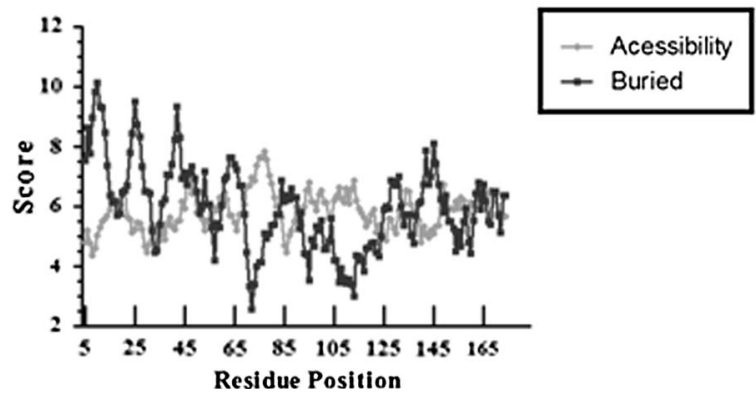


The relative mutability analysis shows that in the first 10 residues, around residues $30-35$ and 105-110; the mutability is lowest. On other hand, from residues 17 to 20,70 to 90 and following residue 120; the highest values of mutability is shown (Fig. 6).

\section{MHC binding sites and epitope predictions}

NetCLT predict 49 potential epitopes in the protein sequence. The epitopes predictions concentrated in two regions: on the aminoterminal (residue 1-40) and on the central region (60-120). A schematic picture summarizing this prediction was built (Fig. 7).

\section{Discussion}

The expansion of number and the application of antiviral drugs is remarkable, mainly in the last decade. Examples from the current repertoire of new antiviral drugs are anti-HIV, anti-CMV, anti-HSV, anti-VZV, anti-RSV, anti-hepatitis viruses and anti-influenza viruses (De Clercq 2001). Development of new antivirals is a subject of recent expansion, thus there is still plenty of improvement needed (De Clercq 2002). In this field, the bioinformatics tools play an essential role. The combination of fast, reliable and wide range application of software analysis is an important advantage of these tools to help in new drugs investigations (Butte and Ito 2012; Wishart 2005).

Herpes simplex virus (HSV) is a very common human pathogenic virus. Clinically, HSV infection may give rise to gingivostomatitis, cold sore, keratitis, encephalitis, and genital herpes. HSV-1 and HSV-2 use several glycoprotein receptor complexes when they enter into the host cells. Both genotypes express the glycoproteins $\mathrm{gB}, \mathrm{gC}, \mathrm{gD}, \mathrm{geH}$ and $\mathrm{gL}$. All except $\mathrm{gC}$ are essential for viral entry, although the absence of $\mathrm{gC}$ does reduce efficiency. $\mathrm{gC}$ makes the first contact with the host cell, binding to heparin sulfate (HS) proteoglycans on the cell surface (Bernard et al. 2007). The herpes simplex virus can enter cells by two pathways: fusion of the envelope with the plasma membrane and by endocytosis. The first one is dependent on the interaction with specific receptors on the cell surface. The second is an auxiliary pathway which involves endocytosis of the envelope capsid and receptor-dependent fusion of the envelope with the membrane of the endocytic vesicle. Both pathways require initially, reversible attachment to the cell surface (Bernard et al. 2007). This first step in entry involves the binding of virion $\mathrm{gC}$ and $\mathrm{gB}$ proteins to cell-surface glycosaminoglycans (GAG). The importance of this step can be demonstrated by observation that enzymatic removal of GAGs results in 10-20 fold decrease in efficiency of plaque formation. In this study, we found that hemolymph exhibits selective inhibitory effect against HSV-1. Four probable pathways might be deduced to their antiviral effects: (Abernathy et al. 2009) blockage of viral binding to the cell receptors; (O'Neill et al. 2003) attenuation of viral replication after entry; (Emery et al. 2004) inhibition of virus release from host cells and (Read and Kurtz 1999) reduction of the inflammatory cytokines "storm" induced by the virus infection. Our results showed the antiviral effects with pre-incubation treatment presented CPE reduction assay with higher inhibitory activity than the simultaneous treatment for recombinant or total hemolymph. Moreover, to corroborate the antiviral activity, a qPCR assay was used to test the in vitro effect of the hemolymph on viral

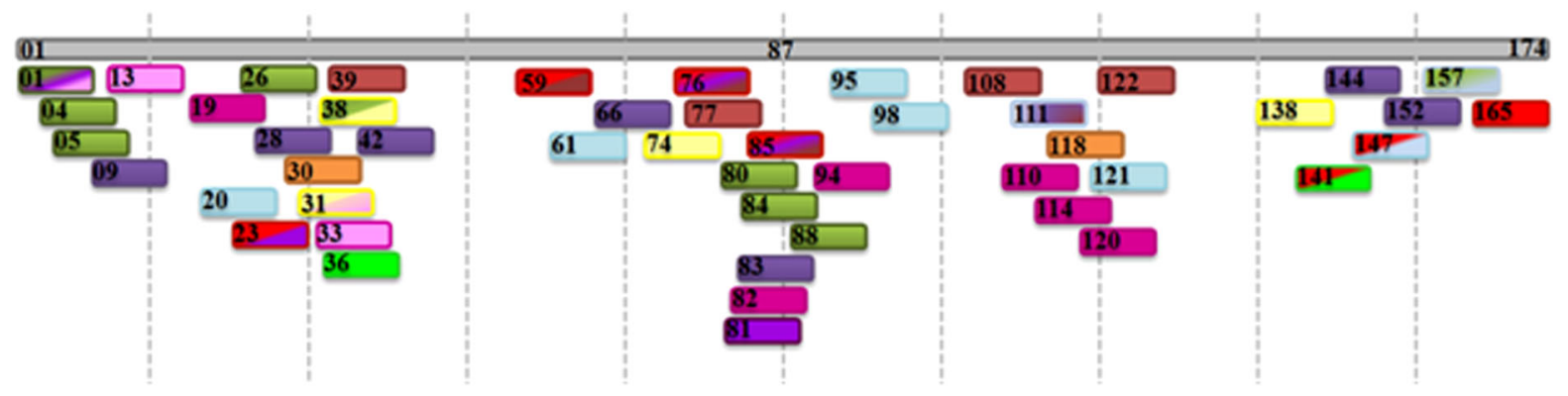

Fig. 7 Epitope prediction results using NetCLT results. The number indicates the first amino acid position of the epitope. Each color represents one MHC allele which binds to the region.
Multicolor bars indicate epitopes recognized by more than one allele. (Color figure online) 
replication (Fig. 2). Olicard et al. (2005) showed that the addition of the hemolymph of $C$. gigas to Vero cell cultures prior to infection with HSV-1 did not affect subsequent infection. Thus, the inhibitory action of the hemolymph on viral replication may be through the activation the IFN pathways. Recently, Melchjorsen et al. (2009) showed the initial response of the cells infected by HSV is secretion of antiviral substances, such as defensins and nitric oxid and, most importantly, the production of cytokines, including IFNs and chemokines. The type I IFNs (IFN- $\alpha \beta)$ are key cytokines produced during the very first hours after HSV infection. In vivo studies show that IFN- $\alpha \beta$ alone controls early HSV infection independently of natural killer (NK) cells and lymphocyte activity (Bernard et al. 2007). Therefore, although studies have established an important role for IFN- $\alpha \beta$ in antiviral defense, it is difficult to determine whether IFN- $\alpha \beta$ contribution to viral clearance is primarily mediated by direct antiviral mechanism or by indirect immunoregulatory mechanisms. In addition, IFN $\lambda$ induces an antiviral state in cells through the Janus kinase-signal transducers and activators of transcription-, the JAK/ STAT pathway (Kotenko 2011; Sheppard et al. 2003). During early HSV infection, activation of multiple cellular transcription factors such as NF- $\mathrm{KB}$, MAPK and IRF is also coordinated (Melchjorsen et al. 2009). Although some therapeutic and diagnostic improvements for control of HSV have been developed during the last years, the virus is by no means under control. The outcome of HSV infections is dependent on the balance between virus propagation and an effective immune response. Appropriate expression of IFNs, cytokines and chemokines is essential for efficient host defense against infection. Maybe, the mechanism of hemolymph includes induction of IFN $\alpha \beta$ expression. Currently, we are studying this suggested hypothesis.

Rubella is classified in the Togaviridae family. The virus contains a single-stranded RNA genome and it is the only member of a separate genus called Rubivirus. The virus particle has a diameter of about $60 \mathrm{~nm}$. There is a nucleocapsid exhibiting cubic symmetry surrounded by a lipoprotein envelope with projections consisting of two glycoproteins (E1 and E2). The high GC content, up to $65 \%$, is the most distinguished characteristic of the viral genome (Hobman and Chantler 2007).
Rubella virus infected cells have a reduced life span. Consequently, in the organs of affected fetuses and infants the number of cells is lower than in healthy ones. Rubella can also induce damage by apoptosis. In vitro studies suggest that this effect is due to a rubella-induced caspase-dependent mechanism. Details of this mechanism are still unclear, but it seems to be dependent on virus replication started within $12 \mathrm{~h}$ of infection. The p53 pathway seems not be involved. However, in nonhuman cells, although viral replication is required to induce apoptosis, it is the non-infected neighboring cells that undergo this effect. In addition, the IFN $\alpha$ and $\gamma$ restrict viral replication, reducing the levels of viral RNA in the cell and inhibiting viral translation. Interestingly, Stanwick and Hallum (1974) found that other cells persistently infected with RUBV [BSC1, BHK (hamster; these cells lack the type I IFN receptor), RK13 (rabbit), and HeLa (human)] were not cured by similar levels of exogenously IFN administration. In conclusion, RUBV persistent infection in cell culture is surprisingly resistant to IFN treatment, likely contributing to the ability of RUBV to establish a persistent infection. Rubella transcription level was also affected by the presence of total hemolymph and rAVLO clones (Fig. 1).

Based on the advantages of in silico tools, the present study proposed the use of bioinformatics available softwares to describe a novel protein which showed antiviral activity. These analyses showed many interesting characteristics of this protein. This protein shows a signal peptide for secretion, which is cleaved. This result is agreeing with the previous experimental analysis that showed this protein as a hemolymph component (Greco et al. 2009). Hemolymph products from different arthropods are potential candidates to treat different diseases in the human body. Promising anticancer agents (Wu et al. 2009), antithrombotic (Guerrero et al. 2011) and antimicrobial agents (Gazit et al. 1994; Slocinska et al. 2008) are some examples.

Overall hydrophobicity analysis showed that this protein is hydrophilic (GRAVY $=-0.306$ ) with predominantly folded regions. Folding is essential to define a stable conformation of the peptide (Potluri et al. 2004). Therefore, in summary, bioinformatics analysis indicated that these physical and chemical properties of the protein may be stable enough to allow successful experimental analysis of structure and interaction. 
Furthermore, Prosite search recognized potential posttranslational modifications sites (Fig. 3). Potential phosphorylation sites were identified in 11 positions. Addition of phosphorus atoms in the protein leads to a reversible modification in protein structure. It is a mechanism used in cell signaling and regulatory pathways (Olsen et al. 2006). Myristoylation sites were found in two positions of the protein. Covalent myristate binding is not reversible and alters the protein hydrophobicity, which is important to the structural maintenance of the macromolecule (Gordon et al. 1991).

Moreover, in silico results pointed to a candidate region for interacting with cell/virus (Fig. 6). Accessibility, polarity and MHC binding pointed to a highly exposed region between residues 70 and 120. Although experimental analyses are still needed for confirmation, this region could interact with virus or cellular proteins inhibiting the establishment of viral infection, primarily at an early stage during the infection.

Summarizing our study, the CPE assay results showed reduction in the replication of the viruses. In addition, qPCR results indicate that there was a small inhibition, unlike what occurred in Vero cells inoculated with herpes. Bioinformatics analysis indicated interesting results. The protein seems to present folding and hydrophilic profiles compatible to future crystallography essays (Figs. 4, 5). A possible region of interaction with cellular and/or viral proteins was also identified (Fig. 7).

It was concluded that the novel protein from hemolymph may act as a potent antiviral agent at different virus types: enveloped viruses (rubella virus, herpes virus, and measles virus), non-enveloped viruses (picornavirus), genomic DNA viruses (herpes virus) and RNA viruses (influenza virus, measles virus and picornavirus) (Carmo et al. 2012; Greco et al. 2009). Further analyses to understand its mechanism of action and applicability in vivo are essential. However, with the previous and present results, we can conclude that this macromolecule has the potential to become a promising antiviral agent with broad spectrum activity.

\section{References}

Abernathy E, Cabezas C, Sun H, Zheng Q, Chen MH, CastilloSolorzano C, Ortiz AC, Osores F, Oliveira L, Whittembury
A, Andrus JK, Helfand RF, Icenogle J (2009) Confirmation of rubella within 4 days of rash onset: comparison of rubella virus RNA detection in oral fluid with immunoglobulin $\mathrm{M}$ detection in serum or oral fluid. J Clin Microbiol 47:182-188. doi:10.1128/JCM.01231-08

Bernard R, David K, Richard W (2007) Herpes virus. In: Knipe DM, Howley PM (eds) Fields virology, vol 1. Lippincott Williams \& Wilkins, Philadelphia, pp 2502-2601

Butte AJ, Ito S (2012) Translational bioinformatics: data-driven drug discovery and development. Clin Pharmacol Ther 91:949-952. doi:10.1038/clpt.2012.55

Carmo AC, Giovanni DN, Corrêa TP, Martins LM, Stocco RC, Suazo CA, Moraes RH, Veiga AB, Mendonça RZ (2012) Expression of an antiviral protein from Lonomia obliqua hemolymph in baculovirus/insect cell system. Antiviral Res 94:126-130. doi:10.1016/j.antiviral.2011.12.010

Chernysh S, Kim SI, Bekker G, Pleskach VA, Filatova NA, Anikin VB, Platonov VG, Bulet P (2002) Antiviral and antitumor peptides from insects. Proc Natl Acad Sci USA 99:12628-12632

Cueto AP, Alves SH, Pilau M, Weiblen R, Kubiça TF, Lovato LT (2011) Atividade antiviral do extrato de própolis contra o calicivírus felino, adenovírus canino 2 e vírus da diarréia viral bovina. Ciência Rural 41:1800-1806

De Clercq E (2001) Antiviral drugs: current state of the art. J Clin Virol 22:73-89

De Clercq E (2002) Strategies in the design of antiviral drugs. Nat Rev Drug Discov 1:13-25. doi:10.1038/nrd703

Delcroix M, Riley LW (2011) Cell-penetrating peptides for antiviral drug development pharmaceuticals. 3:448-470

Dosztanyi Z, Csizmok V, Tompa P, Simon I (2005) The pairwise energy content estimated from amino acid composition discriminates between folded and intrinsically unstructured proteins. J Mol Biol 347:827-839. doi:10. 1016/j.jmb.2005.01.071

Emanuelsson O, Brunak S, von Heijne G, Nielsen H (2007) Locating proteins in the cell using TargetP, SignalP and related tools. Nat Protoc 2:953-971. doi:10.1038/nprot.2007.131

Emery SL, Erdman DD, Bowen MD, Newton BR, Winchell JM, Meyer RF, Tong S, Cook BT, Holloway BP, McCaustland KA, Rota PA, Bankamp B, Lowe LE, Ksiazek TG, Bellini WJ, Anderson LJ (2004) Real-time reverse transcriptionpolymerase chain reaction assay for SARS-associated coronavirus. Emerg Infect Dis 10:311-316

Fiore AE, Fry A, Shay D, Gubareva L, Bresee JS, Uyeki TM (2011) Antiviral agents for the treatment and chemoprophylaxis of influenza-recommendations of the Advisory Committee on Immunization Practices (ACIP). MMWR Recomm Rep 60:1-24

Gazit E, Lee WJ, Brey PT, Shai Y (1994) Mode of action of the antibacterial cecropin B2: a spectrofluorometric study. Biochemistry 33:10681-10692

Gordon JI, Duronio RJ, Rudnick DA, Adams SP, Gokel GW (1991) Protein N-myristoylation. J Biol Chem 266: 8647-8650

Greco KN, Mendonca RM, Moraes RH, Mancini DA, Mendonça RZ (2009) Antiviral activity of the hemolymph of Lonomia obliqua (Lepidoptera: Saturniidae). Antiviral Res 84:84-90. doi:10.1016/j.antiviral.2009.07.018

Guerrero B, Arocha-Pinango CL, Salazar AM, Gil A, Sanchez EE, Rodriguez-Acosta A, Lucena S (2011) The effects of 
Lonomin V, a toxin from the caterpillar (Lonomia achelous), on hemostasis parameters as measured by platelet function. Toxicon Off J Int Soc Toxinol 58:293-303. doi:10.1016/j.toxicon.2011.07.003

Heinen TE, da Veiga AB (2011) Arthropod venoms and cancer. Toxicon 57:497-511. doi:10.1016/j.toxicon.2011.01.002

Hobman T, Chantler J (2007) Rubella virus. In: Knipe DM, Howley PM (eds) Fields virology, vol 1. Lippincott Williams \& Wilkins, Philadelphia, pp 1069-1100

Hunter S, Jones P, Mitchell A, Apweiler R, Attwood TK, Bateman A, Bernard T, Binns D, Bork P, Burge S, de Castro E, Coggill P, Corbett M, Das U, Daugherty L, Duquenne L, Finn RD, Fraser M, Gough J, Haft D, Hulo N, Kahn D, Kelly E, Letunic I, Lonsdale D, Lopez R, Madera M, Maslen J, McAnulla C, McDowall J, McMenamin C, Mi H, Mutowo-Muellenet P, Mulder N, Natale D, Orengo C, Pesseat S, Punta M, Quinn AF, Rivoire C, SangradorVegas A, Selengut JD, Sigrist CJ, Scheremetjew M, Tate J, Thimmajanarthanan $\mathrm{M}$, Thomas $\mathrm{PD}, \mathrm{Wu} \mathrm{CH}$, Yeats $\mathrm{C}$, Yong SY (2012) InterPro in 2011: new developments in the family and domain prediction database. Nucleic Acids Res 40:D306-D312. doi:10.1093/nar/gkr948

Kao RY, Yang D, Lau LS, Tsui WH, Hu L, Dai J, Chan MP, Chan CM, Wang P, Zheng BJ, Sun J, Huang JD, Madar J, Chen G, Chen H, Guan Y, Yuen KY (2010) Identification of influenza A nucleoprotein as an antiviral target. Nat Biotechnol 28:600-605. doi:10.1038/nbt.1638

Kelley LA, Sternberg MJ (2009) Protein structure prediction on the web: a case study using the Phyre server. Nat Protoc 4:363-371. doi:10.1038/nprot.2009.2

Kotenko SV (2011) IFN-lambdas. Curr Opin Immunol 23:583-590. doi:10.1016/j.coi.2011.07.007

Larsen MV, Lundegaard C, Lamberth K, Buus S, Lund O, Nielsen M (2007) Large-scale validation of methods for cytotoxic T-lymphocyte epitope prediction. BMC Bioinform 8:424. doi:10.1186/1471-2105-8-424

Lohner K, Staudegger E (2001) Are we on the threshold of the post-antibiotic era? In: Lohner K (ed) Development of novel antimicrobial agents: emerging strategies. Horizon Scientific Press, England

Melchjorsen J, Matikainen S, Paludan SR (2009) Activation and evasion of innate antiviral immunity by herpes simplex virus. Viruses 1:737-759. doi:10.3390/v1030737viruses01-00737

Olicard C, Renault T, Torhy C, Benmansour A, Bourgougnon N (2005) Putative antiviral activity in hemolymph from adult Pacific oysters, Crassostrea gigas. Antiviral Res 66:147-152

Olsen JV, Blagoev B, Gnad F, Macek B, Kumar C, Mortensen P, Mann M (2006) Global, in vivo, and site-specific phosphorylation dynamics in signaling networks. Cell 127:635-648. doi:10.1016/j.cell.2006.09.026

O'Neill HJ, Wyatt DE, Coyle PV, McCaughey C, Mitchell F (2003) Real-time nested multiplex PCR for the detection of herpes simplex virus types 1 and 2 and varicella zoster virus. J Med Virol 71:557-560. doi:10.1002/jmv.10516

Ourth DD (2004) Antiviral activity against human immunodeficiency virus-1 in vitro by myristoylated-peptide from Heliothis virescens. Biochem Biophys Res Commun 320:190-196

Petersen TN, Brunak S, von Heijne G, Nielsen H (2011) SignalP 4.0: discriminating signal peptides from transmembrane regions. Nat Methods 8:785-786. doi:10.1038/nmeth.1701

Popham HJ, Shelby KS, Brandt SL, Coudron TA (2004) Potent virucidal activity in larval Heliothis virescens plasma against Helicoverpa zea single capsid nucleopolyhedrovirus. J Gen Virol 85:2255-2261

Potluri S, Khan AA, Kuzminykh A, Bujnicki JM, Friedman AM, Bailey-Kellogg C (2004) Geometric analysis of crosslinkability for protein fold discrimination. Pac Symp Biocomput 447-458

Read SJ, Kurtz JB (1999) Laboratory diagnosis of common viral infections of the central nervous system by using a single multiplex PCR screening assay. J Clin Microbiol 37:1352-1355

Reed LJ, Muench H (1938) A simple method of estimating fifty per cent endpoints. Am J Epidemiol 27:493-497

Rost B, Yachdav G, Liu J (2004) The predictprotein server. Nucleic Acids Res 32:W321-W326. doi:10.1093/nar/ gkh37732/suppl_2/W321

Sheppard P, Kindsvogel W, Xu W, Henderson K, Schlutsmeyer S, Whitmore TE, Kuestner R, Garrigues U, Birks C, Roraback J, Ostrander C, Dong D, Shin J, Presnell S, Fox B, Haldeman B, Cooper E, Taft D, Gilbert T, Grant FJ, Tackett M, Krivan W, McKnight G, Clegg C, Foster D, Klucher KM (2003) IL-28, IL-29 and their class II cytokine receptor IL-28R. Nat Immunol 4:63-68. doi:10.1038/ ni873ni873

Slabinski L, Jaroszewski L, Rychlewski L, Wilson IA, Lesley SA, Godzik A (2007) XtalPred: a web server for prediction of protein crystallizability. Bioinformatics 23:3403-3405. doi:10.1093/bioinformatics/btm477

Slocinska M, Marciniak P, Rosinski G (2008) Insects antiviral and anticancer peptides: new leads for the future? Protein Pept Lett 15:578-585

Stanwick TL, Hallum JV (1974) Role of interferon in six cell lines persistently infected with rubella virus. Infect Immun $10: 810-815$

Wishart DS (2005) Bioinformatics in drug development and assessment. Drug Metabol Rev 37:279-310. doi:10.1081/ DMR-55225

Wu JM, Jan PS, Yu HC, Haung HY, Fang HJ, Chang YI, Cheng JW, Chen HM (2009) Structure and function of a custom anticancer peptide, CB1a. Peptides 30:839-848. doi:10. 1016/j.peptides.2009.02.004

Yao H, Wu X, Gokulamma K (2006) Antiviral activity in the mulberry silkworm, Bombyx mori L. J Zhejiang Univ Sci A 7:350-356. doi:10.1631/jzus.2006.AS0350 